\title{
Effects of Ambient Conditions on the Dielectric Properties of Thermally Sprayed Ceramic Coating
}

\author{
M. Niittymäki, B. Rotthier and K. Lahti \\ Department of Electrical Engineering \\ Tampere University of Technology
}

\author{
T. Suhonen and J. Metsäjoki \\ Advanced Materials \\ VTT Technical Research Centre of Finland
}

\begin{abstract}
Thermal spraying techniques are used to manufacture insulating coatings especially for demanding applications like fuel cells where normal insulating materials cannot be used. In electrical insulation applications, the mostly used coating materials are aluminum oxide $\left(\mathrm{Al}_{2} \mathrm{O}_{3}\right)$, magnesium oxide $(\mathrm{MgO})$ and magnesium aluminate $\left(\mathrm{MgAl}_{2} \mathrm{O}_{4}\right)$. Dielectric properties of thermally sprayed ceramic coatings are strongly affected by ambient conditions, and in addition to this they are not well documented in the literature. In this paper the effects of environmental conditions on certain dielectric properties of a thermally sprayed coating are studied. DC resistivity as well as permittivity and losses at different frequencies at relative humidities of $20 \%$ and $45 \%$ at temperature of $20^{\circ} \mathrm{C}, 40{ }^{\circ} \mathrm{C}$ and $60{ }^{\circ} \mathrm{C}$ will be reported in the paper for $\mathrm{Al}_{2} \mathrm{O}_{3}$ samples sprayed using HVOF (High Velocity Oxygen Fuel) technique. DC dielectric breakdown strength is also studied for the HVOF alumina coating at temperature of $20{ }^{\circ} \mathrm{C}$ and relative humidity of $20 \%$ Effects of ambient conditions and coating material composition are also analyzed.
\end{abstract}

\section{Introduction}

Thermally sprayed insulating ceramic coatings can be used in demanding conditions, where for example polymers cannot be used. As an electrically insulating coating the most commonly used materials are aluminum oxide $\left(\mathrm{Al}_{2} \mathrm{O}_{3}\right)$, magnesium oxide $(\mathrm{MgO})$ and magnesium aluminate $\left(\mathrm{MgAl}_{2} \mathrm{O}_{4}\right)$. In general, only little studies of dielectric properties of thermally sprayed ceramic coatings can be found in literature and most of the studies are only focused on the dielectric breakdown strength measurements. In addition, the measurement methods and conditions in previous studies are often not fully documented, and thus the evaluation and comparison of the properties of different coatings is difficult.

Earlier studies of electrical properties of thermally sprayed coatings are mostly concentrated on the HVOF (high velocity oxygen fuel) and plasma sprayed alumina coatings $[1,2,3,4]$. Relative permittivity and dielectric loss behavior for plasma sprayed alumina $\left(\mathrm{Al}_{2} \mathrm{O}_{3}\right)$ coating has been studied in [1] but the results are not fully comparable to this study because of the different spraying technique. In [3], the DC resistance of $\mathrm{HVOF}$ alumina coatings was studied at room temperature (not exactly defined) with relative humidity of $30 \%$ and 95 $\%$, but the DC dielectric breakdown measurements were documented to be performed at room conditions. In $[1,2]$, the DC resistivity and DC dielectric strength of plasma sprayed alumina coatings were studied at room temperature conditions. The results of the papers $[3,4]$ indicate that electrical properties of HVOF sprayed alumina coatings require to be examined more detailed and it has been already seen that especially the microstructure of a coating affects significantly the electrical properties. It has also been indicated that the environmental conditions affect also the electrical properties of thermally sprayed coatings.

In this paper, dielectric properties of one thermally sprayed aluminum oxide coating has been studied in different environmental conditions, concentrating on DC resistivity as well as relative permittivity and dielectric losses as a function of frequency. The measurements were performed at temperature of $20{ }^{\circ} \mathrm{C}$, $40{ }^{\circ} \mathrm{C}$ and $60{ }^{\circ} \mathrm{C}$ and relative humidity of $20 \%$ and $45 \%$. DC dielectric breakdown strength was also studied at temperature of $20^{\circ} \mathrm{C}$ and $\mathrm{RH} 20 \%$.

\section{Experimental}

\subsection{Studied Material}

Commercial $\mathrm{Al}_{2} \mathrm{O}_{3}$-powder was deposited on carbon steel substrate by high velocity oxygen fuel (HVOF) spraying method. Number of studied samples was three (A, B and C). The size of sample $A$ and $C$ was $70 \mathrm{~mm} \mathrm{x}$ $70 \mathrm{~mm}$ and for sample B it was $150 \mathrm{~mm}$ x $150 \mathrm{~mm}$. The porosity of the coating was measured by optical micrographs and it was defined from three samples which were deposited at same time with samples A, B and $\mathrm{C}$. The average porosity value of these three specimens was $1.40 \% \mathrm{vol}$, indicating a rather low porosity for HVOF coating.

The coating thicknesses of the samples were defined from cross section figures of the samples (deposited at the same time with samples A, B and C) and by magnetic measuring device (Elcometer 456C). In the latter case, the thickness result of a sample is an average value of 10 measurements made along the electrode area. The measurement results are presented in Table 1 . In Fig. 1, the cross-section figures of the studied coating are shown. Some deviation is noticed in the thickness values because the substrate is not smooth due to the 
sandblasting of the substrate before depositing the ceramic coating. In addtion to that, the coating itself has lamellar microstructure causing a sligthly non-smooth surface (Fig. 1).

\subsection{Sample Preparation}

Measurements were made at temperatures of $20^{\circ} \mathrm{C}, 40$ ${ }^{\circ} \mathrm{C}$ and $60{ }^{\circ} \mathrm{C}$ and at relative humidities of $20 \%$ and 45

$\%$. The dielectric breakdown strength measurements were, anyhow, performed at temperature of $20{ }^{\circ} \mathrm{C}$ and RH $20 \%$. These conditions were maintained at the climate room of TUT High voltage laboratory. At first, the samples were preconditioned at $120{ }^{\circ} \mathrm{C}$ for two hours and then stabilized at $20{ }^{\circ} \mathrm{C}$ and $\mathrm{RH} 20 \%$ for 12 hours before the actual conditioning at test conditions. In the final conditioning, the samples were maintained at the measurement conditions for four hours just before the measurements to stabilise the coatings. These conditions were also maintained during the whole measuring period.

Before any conditioning of samples $\mathrm{A}$ and $\mathrm{B}$, a round silver electrode was painted on the middle of the coatings. The diameter of the electrode was $50 \mathrm{~mm}$ for sample A and $55 \mathrm{~mm}$ for sample B. In addition, a shield electrode was painted around the measuring electrode to neglect possible surface currents. From cross section figures it was studied that the used high purity silver paint did not penetrate inside the studied thermally sprayed coating.

\subsection{Resistivity}

Resistivity measurements were made using Keithley 6517B electrometer and a measurement bench in which a sample is clamped between two stainless steel electrodes (diameter of $50 \mathrm{~mm}$ ). The test voltage was maintained until a stabilized current level (i.e. pure resistive current) was reached. In practice, the tests were performed at electric fields of $0.5 \mathrm{~V} / \mu \mathrm{m}$ and $1 \mathrm{~V} / \mu \mathrm{m}$ and the stabilized DC current was measured $1000 \mathrm{~s}$ after voltage application. The volume resistivity of a material was thus defined according to IEC standard 60093 (or ASTM D257-07). [5,6]

Table 1. Coating thicknesses of samples A, B and C by magnetic measurement and coating thickness defined from cross-section figure.

\begin{tabular}{|l|c|c|c|c|}
\cline { 2 - 5 } \multicolumn{1}{c|}{} & \multicolumn{3}{c|}{ Magnetic measurement } & $\begin{array}{c}\text { Cross- } \\
\text { section } \\
\text { figure }\end{array}$ \\
\hline Sample & A & B & C & \\
\hline $\begin{array}{l}\text { Average } \\
\text { thickness } \\
(\boldsymbol{\mu m})\end{array}$ & 279 & 265 & 266 & 333 \\
\hline $\begin{array}{l}\text { Thickness } \\
\text { range }(\boldsymbol{\mu m})\end{array}$ & $\begin{array}{c}267- \\
289\end{array}$ & $\begin{array}{c}254- \\
275\end{array}$ & $257-$ & $330-335$ \\
\hline $\begin{array}{l}\text { Standard } \\
\text { deviation } \\
(\mu \mathrm{m})\end{array}$ & 7.3 & - & 7.0 & 2.9 \\
\hline
\end{tabular}

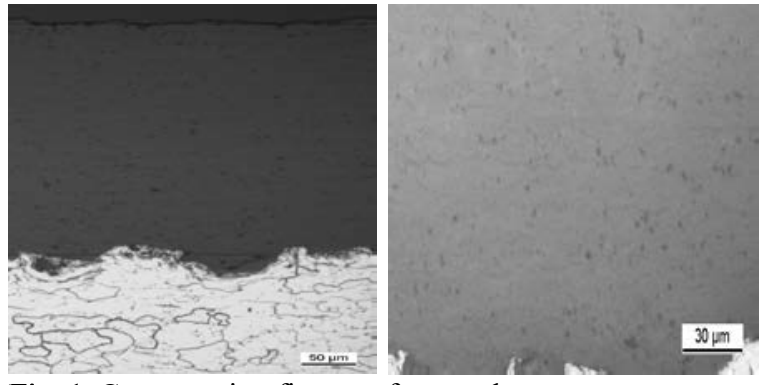

Fig. 1. Cross-section figures of a sample.

\subsection{Dielectric Spectroscopy}

Relative permittivity and dielectric losses of the material was studied with an insulating diagnosis (IDA 200) analyzer device. During the measurements, a sinusoidal voltage with varying frequency was applied over the sample. The true RMS value of the measuring voltage was $140 \mathrm{~V}$. The complex impedance of a sample was calculated from the measured test voltage and the current through a sample which can be expressed as the equivalent parallel RC circuit model (Fig. 2). The relative permittivity $\left(\varepsilon_{r}\right)$ and dissipation factor $(\tan \delta)$ were calculated from the measured parallel resistance and capacitance with Eq. (1-2),

$$
\begin{gathered}
\varepsilon_{r} \approx \varepsilon_{r}^{\prime}=\frac{C_{p}}{C_{0}}-\frac{C_{e}}{C_{0}} \\
\tan \delta=\frac{1}{R_{p} C_{0} \omega}
\end{gathered}
$$

where $C_{p}$ is the measured parallel capacitance and $R_{p}$ the parallel resistance of the equivalent circuit model (Fig. 2). $C_{0}$ is the so called geometric capacitance of test sample (vacuum in place of the insulation) and $\omega$ is angular frequency. The edge field correction $\left(C_{e}\right)$ was used because the shield electrode was rather far away from the measuring electrode. All the test sample arrangements and the edge field correction were according to IEC standard 60250 [7].

Loss index, $\varepsilon_{r}$ ", includes all losses of a sample: both conductive and dielectric ones. It can be defined from relative permittivity and dissipation factor, $\tan \delta$, with Eq. (3).

$$
\varepsilon_{r}^{\prime \prime}=\varepsilon_{r} \tan \delta
$$

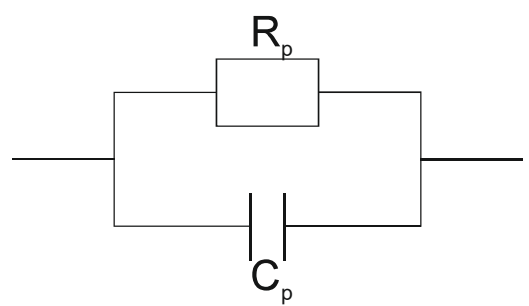

Fig. 2. Equivalent $\mathrm{RC}$ parallel electrical circuit used in dielectric spectroscopy measurements. 


\subsection{Dielectric Breakdown strength}

Breakdown voltage measurements were made with linearly ramped DC voltage at temperature of $20{ }^{\circ} \mathrm{C}$ and relative humidity of $20 \%$. The measurements were made without immersing the samples into transformer oil because it has been found that the oil immerses into the porous coating and thus increases the dielectric strength of a coating. The used electrode was a flat ended stainless steel rod with a diameter of $10 \mathrm{~mm}$ and edge rounding radius of $1 \mathrm{~mm}$. No painted, sputtered or by other means embedded electrodes on the specimen surface were used. The ramp rate of the test voltage was $100 \mathrm{~V} / \mathrm{s}$ throughout the test.

After the breakdown voltage was measured, the thickness of the coating was measured from the breakdown point to define exactly the dielectric breakdown field strength of each breakdown point. The thicknesses were measured with a magnetic measuring device (Elcometer 6517B). Dielectric breakdown field strength of a coating was calculated dividing the breakdown voltage by the corresponding thickness of the breakdown point. The average value of dielectric strength of a sample was calculated from five parallel test results.

\section{Results and Discussion}

\subsection{Resistivity}

DC conductivity of insulation materials is usually dependent on temperature so that an increase in temperature increases the conductivity and thus the resistivity of an insulator decreases with increasing temperature. Table 2 presents the DC resistivity values of the studied HVOF coating in different environmental conditions. The absolute humidity of air in every condition is also listed. Fig. 3 illustrates the DC resistivity as function of temperature when the relative humidity was $20 \%$ or $45 \%$. It can be observed that the resistivity of the HVOF alumina coating decreased strongly when the temperature (and absolute humidity) increased. The change in resistivity was approximately 2 decades at the studied temperature range in the case of higher humidity and about 1.5 decades at the relative humidity $20 \%$. It can be also noticed that the resistivity seems to decrease with field strength. This phenomenon will be studied more detailed later.

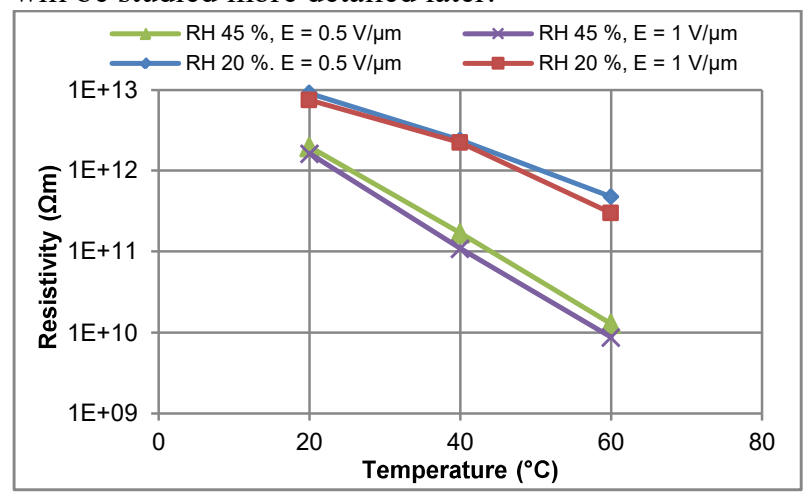

Fig. 3: Resistivity of sample $A$ as a function of temperature, when the relative humidity was either $20 \%$ or $45 \%$.
Table 2. Resistivity values for sample in various ambient conditions.

\begin{tabular}{|r|r|r|r|r|r|}
\hline & \multicolumn{1}{|c|}{} & & & \\
\hline $\mathrm{A}$ & 20 & 20 & 3.5 & 0.5 & $9.08 \mathrm{E}+12$ \\
\hline $\mathrm{A}$ & 40 & 20 & 10.3 & 0.5 & $2.38 \mathrm{E}+12$ \\
\hline $\mathrm{A}$ & 60 & 20 & 26.1 & 0.5 & $4.76 \mathrm{E}+11$ \\
\hline $\mathrm{A}$ & 20 & 20 & 3.5 & 1 & $7.48 \mathrm{E}+12$ \\
\hline $\mathrm{A}$ & 40 & 20 & 10.3 & 1 & $2.22 \mathrm{E}+12$ \\
\hline $\mathrm{A}$ & 60 & 20 & 26.1 & 1 & $2.99 \mathrm{E}+11$ \\
\hline $\mathrm{A}$ & 20 & 45 & 7.8 & 0.5 & $1.95 \mathrm{E}+12$ \\
\hline $\mathrm{A}$ & 40 & 45 & 23.1 & 0.5 & $1.68 \mathrm{E}+11$ \\
\hline $\mathrm{A}$ & 60 & 45 & 58.7 & 0.5 & $1.28 \mathrm{E}+10$ \\
\hline $\mathrm{A}$ & 20 & 45 & 7.8 & 1 & $1.62 \mathrm{E}+12$ \\
\hline $\mathrm{A}$ & 40 & 45 & 23.1 & 1 & $1.08 \mathrm{E}+11$ \\
\hline $\mathrm{A}$ & 60 & 45 & 58.7 & 1 & $8.72 \mathrm{E}+09$ \\
\hline
\end{tabular}

\subsection{Dielectric Spectroscopy}

Table 3 presents the relative permittivity and loss index of sample B in various conditions and it can be observed that increasing the temperature increases both the losses and the relative permittivity. In [1], the relative permittivity of plasma sprayed alumina coating was $6-$ 8 at $1 \mathrm{kHz}$ when the samples were preconditioned 1-3 days at $120{ }^{\circ} \mathrm{C}$. Measurement conditions were not documented in the paper but it may be assumed that room temperature conditions have been used in the tests. Because of the different spraying technique and measurement arrangements, the results are not fully comparable to the results of this study. Now the measured relative permittivity was 11.6 at $1 \mathrm{kHz}$ at temperature of $20{ }^{\circ} \mathrm{C}$ and $\mathrm{RH}$ of $45 \%$. Relative permittivity of bulk $\mathrm{Al}_{2} \mathrm{O}_{3}$ at $1 \mathrm{MHz}$ has been reported to be 9 and 9.8 at alumina purities of $96 \%$ and $99 \%$, respectively [8].

Figs. 4 and 5 illustrate the relative permittivity as function of frequency in different temperatures at the relative humidity of $20 \%$ and $45 \%$, respectively. It has to be kept in mind that when the relative humidity is kept constant at different temperatures, the absolute amount of humidity increases with the temperature (Table 3). The increase in permittivity as a function of temperature in Figs. 4 and 5 is thus not only due to temperature.

Loss index of sample B as a function of temperature is presented in Fig. 6 when the relative humidity was 20 $\%$. Similarly Fig. 7 illustrates the losses at relative humidity of $45 \%$.

As expected, the losses increase remarkably with temperature and ambient humidity. Strong effect due to humidity may be understood based on the microstructure and the hydrophilic nature of the coating. The coating consists of a lamellar structure with fast 
cooled/crystallized interfaces between bulk areas with some gas voids in the interfacial areas (Fig. 1). The dielectric properties of these areas are probably different enhancing interfacial polarization and the losses in the material. The losses seem to increase especially at the lowest frequencies indicating dominating increase due to conduction, which is also seen in the resistivity results.

Table 3. Relative permittivity and loss index of sample B at frequency of $50 \mathrm{~Hz}$.

\begin{tabular}{|c|c|c|c|c|c|}
\hline 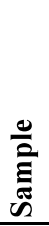 & 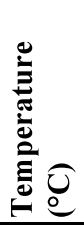 & 昰 & 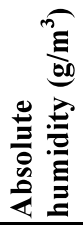 & N & 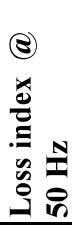 \\
\hline B & 20 & 20 & 3.5 & 10.4 & 3.1 \\
\hline B & 40 & 20 & 10.3 & 13.9 & 6.6 \\
\hline B & 60 & 20 & 26.1 & 20.3 & 12.2 \\
\hline $\mathrm{B}$ & 20 & 45 & 7.8 & 28.8 & 15.6 \\
\hline $\mathrm{B}$ & 40 & 45 & 23.1 & 48.2 & 22.4 \\
\hline B & 60 & 45 & 58.7 & 68.5 & 33.3 \\
\hline
\end{tabular}

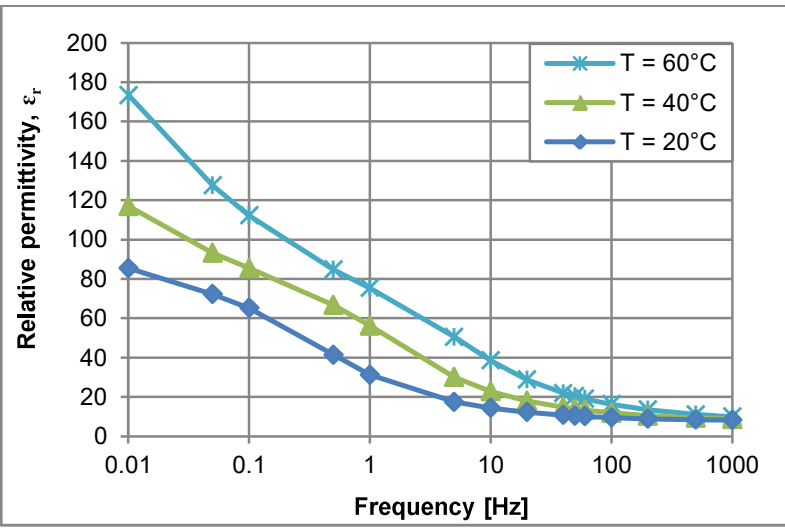

Fig. 4. Relative permittivity of sample $B$ as a function of frequency at various temperatures at relative humidity of $20 \%$.

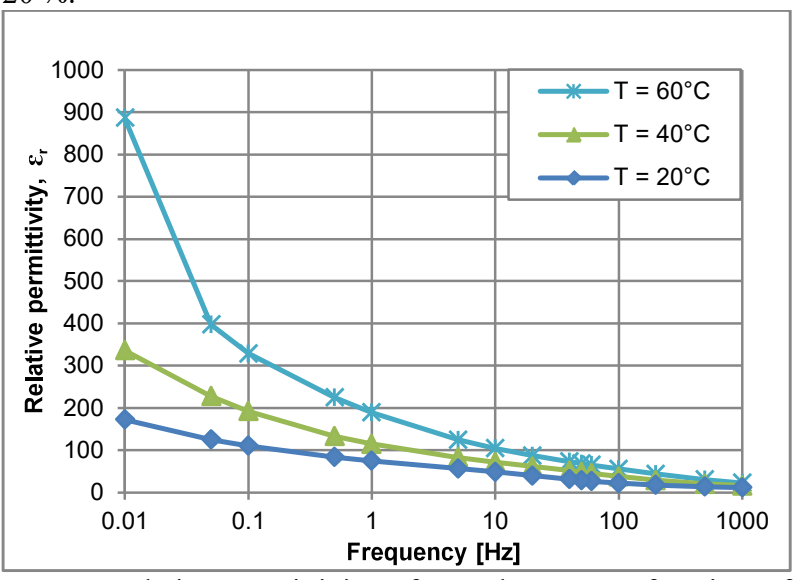

Fig. 5. Relative permittivity of sample $B$ as a function of frequency at various temperatures at relative humidity of $45 \%$.

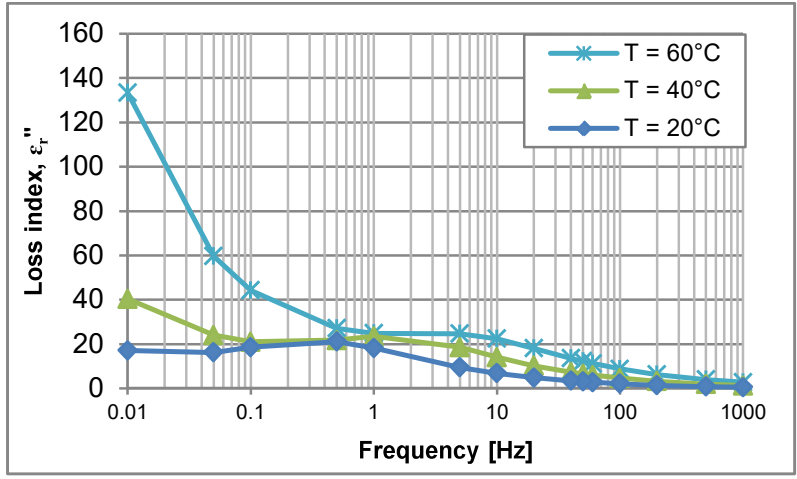

Fig. 6. Loss index of sample $B$ as a function of frequency at various temperatures at relative humidity of $20 \%$.

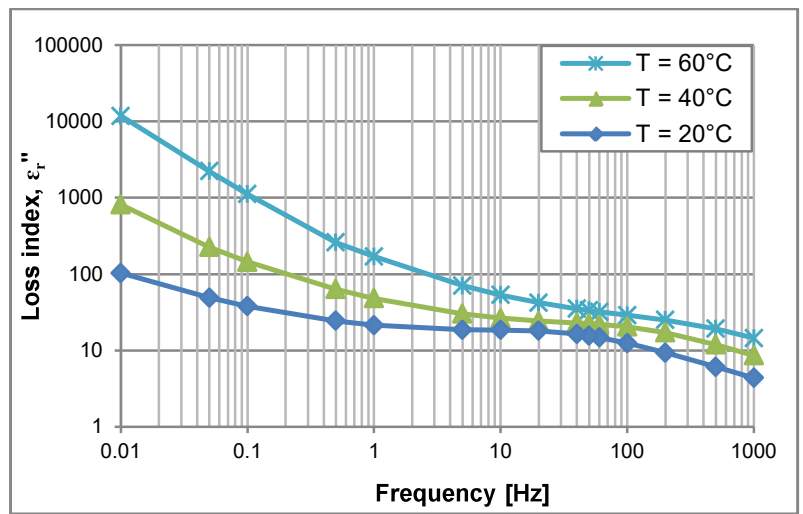

Fig. 7. Loss index of sample $B$ as a function of frequency at various temperatures at relative humidity of $45 \%$.

\subsection{Dielectric Breakdown Strength}

Table 4 presents the DC dielectric breakdown strength for sample $\mathrm{C}$ at temperature of $20{ }^{\circ} \mathrm{C}$ and at $\mathrm{RH} 20 \%$. Only five parallel breakdown results were measured due to shortage of material samples.

In [3], the DC dielectric breakdown strength of HVOF sprayed alumina coating was $\sim 34 \mathrm{~V} / \mu \mathrm{m}$ at room temperature conditions when the thicknesses of the samples were approximately $120 \mu \mathrm{m}$. In similar conditions the DC dielectric strength was $\sim 22 \mathrm{~V} / \mu \mathrm{m}$, when the thickness of the HVOF coatings was approximately $200 \mu \mathrm{m}$ [3]. In [4], the DC dielectric breakdown strength was studied for suspension HVOF and HVOF sprayed alumina coatings and the results were $19.5-26.8 \mathrm{~V} / \mu \mathrm{m}$ (thickness of a sample $60-200$ $\mu \mathrm{m}$ ) and $22.5 \mathrm{~V} / \mu \mathrm{m}$ (thickness of a sample $200 \mu \mathrm{m}$ ), respectively. The measurement conditions in $[3,4]$ are not fully documented and because of that the results of those papers cannot be fully compared to results of this paper. Anyhow, with some uncertainty it may be evaluated that the breakdown strength of the HVOF coating studied in this paper is at least as high as reported in $[3,4]$ or higher. 
Table 4. DC dielectric breakdown strength.

\begin{tabular}{|c|c|c|c|c|c|c|}
\hline 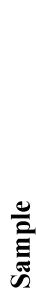 & 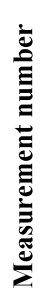 & 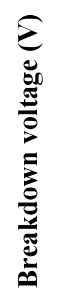 & 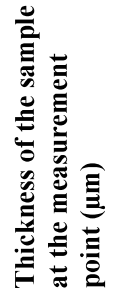 & 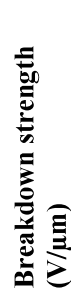 & 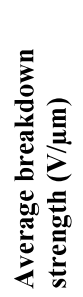 & 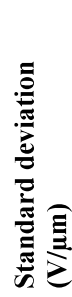 \\
\hline \multirow[t]{5}{*}{$\mathrm{C}$} & 1 & 8100 & 259 & 31.3 & 31.3 & 2.1 \\
\hline & 2 & 7725 & 272 & 28.4 & & \\
\hline & 3 & 8340 & 274 & 30.4 & & \\
\hline & 4 & 8650 & 261 & 33.2 & & \\
\hline & 5 & 8800 & 264 & 33.3 & & \\
\hline
\end{tabular}

\section{Conclusions}

The DC resistivity of the studied HVOF alumina coating was found to be strongly temperature and humidity dependent. It decreased strongly when the temperature and humidity increased. The change was approximately 3 decades at the studied temperature and humidity range.

The dielectric losses and relative permittivity of the HVOF sprayed alumina coatings were also remarkably affected by environmental conditions. Because the coating has a hydrophilic nature and it consists of lamellar microstructure with interfaces, bulk material and voids, this special structure probably affect the dielectric properties of the coating especially at high humidity and temperature levels.

The DC dielectric breakdown strength of the studied alumina coating at $20^{\circ} \mathrm{C}$ and $\mathrm{RH} 20 \%$ was measured to be $31 \mathrm{~V} / \mu \mathrm{m}$ which may be speculated to be at least in the same range than what has been reported in the earlier publications.

Alumina coatings deposited by other spraying techniques than HVOF (for example plasma sprayed) and also bulk alumina will be studied in the future to understand better the dielectric properties of alumina.

\section{References}

[1] L. Pawłowski, "The relationship between structure and dielectric properties in plasma-sprayed alumina coatings," Surface and Coatings Technology, vol. 35, pp. 285-298, 1988.

[2] M. Prudenziati, "Development and the implementation of high-temperature reliable heaters in plasma spray technology," Journal of Thermal Spray Technology, vol. 17, pp. 234-243, 2008.

[3] F.L. Toma, S. Scheitz, L.M. Berger, V. Sauchuk, M. Kusnezoff and S. Thiele, "Comparative study of the electrical properties and characteristics of thermally sprayed alumina and spinel coatings," Journal of Thermal Spray Technology, vol. 20, pp. 195-204, 2011.

[4] F.L. Toma, L.M. Berger, S. Scheitz, S. Langner, C. Rödel, A. Potthoff, V. Sauchuk and M. Kusnezoff, "Comparison of the Microstructural Characteristics and Electrical Properties of Thermally Sprayed $\mathrm{Al}_{2} \mathrm{O}_{3}$ Coatings from Aqueous Suspensions and Feedstock Powders," Journal of Thermal Spray Technology, vol. 21, pp. 480-488, 2012

[5] "Standard Test Methods for DC Resistance and Conductance of Insulating Materials," ASTM Standard D257 - 07, 2007.

[6] "Methods of test for volume resistivity and surface resistivity of solid electrical insulating materials," IEC Standard 60093, 1980.

[7] "Recommended methods for the determination of the permittivity and dielectric dissipation factor of electrical insulating materials at power, audio and radio frequencies including metre wavelengths," IEC Standard 60250, 1969.

[8] H. Yanagida, K. Koumoto, M. Miyayama, The Chemistry of Ceramics, Baffins Lane, Chichester, West Sussex PO19 1 UD, England: John Wiley \& Sons Ltd, 1996. 